\title{
Interventions to reduce discrimination and stigma: the state of the art
}

\author{
Petra C. Gronholm ${ }^{1}$ Claire Henderson ${ }^{1}$ (D) Tanya Deb $^{1} \cdot$ Graham Thornicroft $^{1}$
}

Received: 20 October 2016 / Accepted: 10 January 2017 / Published online: 31 January 2017

(C) The Author(s) 2017. This article is published with open access at Springerlink.com

\begin{abstract}
Background There is a rich literature on the nature of mental health-related stigma and the processes by which it severely affects the life chances of people with mental health problems. However, applying this knowledge to deliver and evaluate interventions to reduce discrimination and stigma in a lasting way is a complex and long-term challenge.

Methods We conducted a narrative synthesis of systematic reviews published since 2012, and supplemented this with papers published subsequently as examples of more recent work.

Results There is evidence for small to moderate positive impacts of both mass media campaigns and interventions for target groups in terms of stigma-related knowledge, attitudes, and intended behaviour in terms of desire for contact. However, the limited evidence from longer follow-up times suggests that it is not clear whether short-term contact interventions have a lasting impact.

Conclusions The risk that short-term interventions may only have a short-term impact suggests a need to study longer term interventions and to use interim process and outcome data to improve interventions along the way. There is scope for more thorough application of intergroup contact theory whenever contact is used and of evidence-based
\end{abstract}

P. C. Gronholm and C. Henderson are Joint first authors.

Claire Henderson

Claire.1.Henderson@kcl.ac.uk

1 Health Services and Population Research Department P029, David Goldberg Centre, King's College, London Institute of Psychiatry, Psychology and Neuroscience, De Crespigny Park, London SE5 8AF, UK teaching and assessment methods when skills training is used for target groups.

Keywords Discrimination - Stigma $\cdot$ Mental disorders · Attitudes $\cdot$ Behaviour $\cdot$ Intergroup contact

\section{Introduction}

Mental health-related discrimination and stigma are global, multifaceted problems. Research and intervention in this field have applied a variety of definitions, targets and outcomes. An overview of these means of describing, clarifying and classifying the stigma concept is provided by, for example, Pescosolido and Martin [1]. They outlined two broad perspectives - experiential and action-orientatedthrough which stigma can be categorised.

The experiential perspective distinguishes between whether stigma is (1) perceived (a belief "most people" are considered to hold), (2) endorsed (expressing agreement with stereotypes/prejudice/discrimination), (3) anticipated (expecting an experience of prejudice/discrimination), (4) received (overt experiences of rejection or devaluation), or (5) enacted (exhibiting discriminatory behaviours).

The action-oriented view considers who (or what) gives or receives the stigma. From this perspective, distinctions are made between (1) public stigma (stereotypes, prejudice and discrimination as endorsed by the general population); (2) structural stigma (prejudice and discrimination through laws, policies, and constitutional practices); (3) courtesy stigma (stereotypes, prejudice and discrimination acquired through a connexion with a stigmatised group/person); (4) provider-based stigma (prejudice and discrimination by occupational groups designated to provide assistance to stigmatised groups), and; (5) self-stigma (when people 
who belong to a stigmatised group legitimise publicly held stereotypes and prejudice, and internalise these by applying them to themselves).

As expected for such a multifaceted phenomenon, the impacts of experienced and anticipated discrimination in combination are severe: poor access to mental [2,3], and physical healthcare [4]; reduced life expectancy [5, 6]; exclusion from higher education [7, 8] and employment [9]; increased risk of contact with criminal justice systems; victimisation [10]; poverty and homelessness. For many people, these consequences have been described as worse than the experience of the mental illness itself [11]. While there is more than one theory of stigma, they share an understanding that it constitutes a significant public health concern $[12,13]$. Some governments and non-governmental organisations have also recognised this. One of the six key objectives of the UK Government's mental health strategy 2011-15 specified the need to ensure fewer people experience stigma and discrimination due to their mental illness [14]. The World Health Organisations' Mental Health Action Plan 2013-2020 specifies that people affected by mental illness should be able to participate fully in society and at work, free from stigmatisation and discrimination [15].

\section{Anti-stigma interventions: the state of the art}

In common with any public health intervention, programmes to reduce discrimination and stigma must be based on a series of decisions, in this case: the scope to mental disorders to be included, whether explicitly or implicitly; the level of intervention, whether structural, interpersonal, or self-stigma; whether to take a whole population approach versus choosing target groups, and if the latter, which groups are priority targets in terms of either the frequency and/or severity of the impact on people with mental health problems; what approach an intervention for a given group and at a given level should take; and how to evaluate the impact.

It is to be hoped that these decisions will be based on existing evidence and developmental work carried out by those delivering a programme. However, it seems likely that decision-making will also reflect who the decisionmakers are. Traditionally, anti-stigma programmes were conducted by or with considerable involvement from groups representing psychiatric expertise such as the World Psychiatric Association and Royal College of Psychiatrists (regarding programmes in the UK). However, more recent programmes have greater leadership from advocacy groups and mental health charities. These groups have often identified mental health professionals as a source of stigmatisation and question whether they are therefore in a credible position to lead anti-stigma programmes [16]. Another potentially important influence on decision-making and credibility is the source of programme funding. For example, pharmaceutical company involvement may be perceived as a self-interested attempt to expand the market for psychotropic medicine as a result of increased help-seeking, on which stigma has a negative impact [2]. Government funding may be perceived as affecting the choice of targets or methods for a programme; this will be discussed later when we consider interventions to reduce structural discrimination.

Anti-stigma strategies have been categorised in terms of education (replacing myths about mental illness with accurate knowledge), contact (using direct or indirect-i.e. parasocial-interactions with people who have a mental illness to challenge prejudice), and protest (attempts to suppress stigmatising attitudes and representations of mental illness) [17]. Education and contact have been found to be the most commonly used. However, it should be noted that educational approaches vary widely in terms of what information they aim to convey. For example, mental health literacy programmes aim to increase knowledge of mental health problems, improve attitudes, and stimulate helping behaviours, [18-20], while rights-based programmes such as See Me in Scotland (https://www.seemescotland.org/ our-movement-for-change/change-networks/human-rights/) focus on the legal rights of people with mental health problems.

Early anti-stigma efforts often used educational approaches. For example, work in the 1950s by Cumming and Cumming in a town in Canada [21] attempted to reduce stigma through providing mental health education via group discussions and films. Also in the UK, the 'Defeat Depression' campaign in the early 1990s aimed to reduce stigma through provision of information on depression for the public and professionals [22]. Interventions for health professionals often rely on educational approaches [23]. Over time, the use of intergroup contact has increased, especially following a meta-analysis by Corrigan and colleagues in 2012 which highlighted its effectiveness [24]. Below, we discuss how these approaches have been used both separately and together in population-level interventions and those targeted to specific groups.

\section{Anti-stigma interventions for the general public}

At the time of writing, there has been a proliferation of national and regional programmes which have either recently finished or are ongoing. The summary below exemplifies the state of the art rather than providing a comprehensive description. 'Beyondblue' is a depressionspecific programme in Australia which has been associated 
with improved public attitude and knowledge [25], with greater effects associated with greater exposure to the programme [26]. The 'Like Minds, Like Mine' anti-stigma programme in New Zealand resulted in reduced overall levels of discrimination [27], and there have also been indications of improved knowledge and attitudes following this work. 'See Me' is a national programme aiming to end mental health-related stigma and discrimination running in Scotland. When the findings of cross-sectional population surveys of public attitudes towards people with mental illness between 1994 and 2003 were compared between Scotland and England (where no comparable programme was underway), attitudes in England were significantly deteriorating whereas no comparable pattern was noted in Scotland where attitudes remained largely unchanged [28]. The 'Hjärnkoll' programme in Sweden started in 2010; by 2014, its contact-based strategy had achieved a positive impact on mental health literacy, attitudes and intended social contact with people with mental illness [29].

The 'Time to Change' programme in England (launched in 2008) and 'Opening Minds' in Canada (launched in 2009) [30] allow comparison of two programmes adhering to different frameworks. Whereas the Time to Change programme used a public health perspective, defining stigma in terms of problems relating to knowledge, attitudes and behaviours [11, 31], the Opening Minds programme used a sociological framework where stigma is considered reflective of the co-occurrence of labelling, stereotyping, separation, status loss and discrimination [32, 33]. Both programmes were built on evidence-based approaches to stigma reduction, with an emphasis on contact-based education strategies. There were, however, differences in how these strategies were delivered. Time to Change primarily aimed to target the general population via large-scale mass media social marketing campaigning. The initial focus was on education-based "myth busting", followed by a focus on reducing prejudice and changing behaviours. Additionally, Time to Change involved local initiatives and work with target groups such as medical students and employers $[34,35]$. In contrast, Opening Minds did not include a mass media element, after a short-term media campaign suggested little or no impact on stigma-related knowledge or desire for social distance [36]. Rather, it focused solely on intensive, targeted work with specific target groups across the country-young people, healthcare providers, the news media and the workforce-through grassroots input and community programmes [36].

Systematic academic evaluation has been carried out on several programme components of both Time to Change and Opening Minds, and on the overall impact of Time to Change among the general population and among users of mental health services [30]. The results of these evaluations indicate that both programmes have been successful in reducing stigma. In England, following Time to Change, benefits were observed in terms of population-level improvements in stigma-related knowledge, attitudes, social distance and reported contact with people having mental illness, albeit some of these effects emerged slowly [37, 38]. Positive changes were also evident in mental health service users' reduced reporting of experiences of discrimination [39]. Population-level changes were not achievable in Canada as the programme was conducted on a local level. Evaluation of these local efforts did, however, indicate positive changes. For example, interventions focusing on high school students were generally successful in improving students' intended behaviour towards people with a mental illness [40], and similarly, programmes amongst healthcare providers generally produced positive results in terms of their attitudes [41]. The goal within Opening Minds is to replicate successful programmes nationally; this work currently involves a national scale-up underway with the efforts focusing on young people.

Regarding identifying mechanisms of successful stigma change, albeit Time to Change included smaller efforts with a local or target focus, the intended population-level exposure to the mass media elements of the programme makes it impossible to examine the impact of these components separately. In contrast, Opening Minds built on community-based efforts only, which were all based on contact-based education strategies but were heterogeneous in nature [30]. This variability has enabled identification of how to effectively tailor stigma interventions for different populations [41], and what the effective programme ingredients are [42]. These findings are discussed further below in relation to work focused on key target groups.

\section{Anti-stigma interventions for key target groups}

Stigma reduction within specific groups can in theory advance life opportunities for people with mental illness $[11,43]$. Target groups have been identified on the basis of: high levels of contact with service users (healthcare professionals), position of power (law enforcement officers), or potential for changing the future (students and young people) [43].

\section{Healthcare professionals}

Evidence regarding anti-stigma efforts amongst healthcare professionals has been discussed, for example, by Henderson and colleagues [23]. Their review identified 16 intervention studies examining stigma reduction in relation to mental health generally or specific mental health conditions (e.g. borderline personality disorder, substance misuse) amongst various groups of healthcare and mental 
healthcare professionals. Most interventions were educational but examined attitudinal outcomes which were generally reported to have improved following the intervention. Some studies also reported improved knowledge, behavioural intentions and/or clinical competence. When followup assessments were conducted these generally indicated that the positive changes had been sustained (e.g. [44, 45]), however, only a few studies had examined this.

Two studies had examined internet-based stigma reduction in relation to mental illness in general. In the first, significantly lowered scores for social distance were reported amongst Turkish psychiatrists randomly assigned to receive an instructional email about stigma, compared to controls who received a questionnaire on social distance [46]. However, this study did not include any baseline measures; a major methodological weakness. The other intervention comprised internet-based education on mental illness to professionals working in long-term care facilities in the USA, following which significant positive differences were found for all outcomes including measures of knowledge, attitudes (stereotype endorsement), empathy, self-efficacy and intended behaviour [47].

Face to face stigma reduction training for healthcare providers was conducted within Canada's Opening Minds antistigma programme [48]. Thirty-seven contact-based education programmes were evaluated using a mixed methods approach, to identify the key ingredients associated with attitude change [42]; no behavioural measures were used. Table 1 provides a summary of these findings; multiple forms of contact and an emphasis on recovery were identified as the most critical ingredients.

\section{Police officers}

Criminal justice professionals are another key group for stigma reduction interventions [43]. The deinstitutionalisation of mental health services has led to a significant increase in contact between the police and those with mental illness, and it has been argued that police officers should be provided education and training to improve the outcomes of their interaction with people with mental illness. Few studies have been conducted in this area, but evidence from two is summarised below.

Pinfold and colleagues [49] evaluated a training intervention with one police force in England. Police officers' $(n=109)$ knowledge, attitudes and behavioural intentions in relation to mental illness were assessed before and after attending two educational workshops delivered by service users, carers and people working in the field of mental health. The results indicated no changes in perceived knowledge. Also, although the intervention produced some improvements in reported attitudes, the stereotype linking people with mental health problems with violent behaviour was not successfully challenged. However, a third of the participants reported positive impacts on police work at follow-up, particularly improvements in communication between officers and persons with mental health problems.

Hansson and colleagues [50] examined the effectiveness of an anti-stigma intervention in a police officer training programme in Sweden $(n=120)$, through a controlled pre-post intervention study design with a comparison group and 6-month follow-up of the intervention group. They found that the intervention improved police officers' attitudes, mental health literacy and intentional behaviours. These changes were generally still present 6 months later. The intervention was well received amongst the trainees, and some of its key elements have been retained in the regional police training programme.

\section{Students}

A systematic review of the overall effect of variety of interventions delivered to student groups [51] identified 35 studies (involving 4257 students) covering a range of interventions including contact with a person with mental health problems, and education via text, lecture, film or role play. Narrative synthesis indicated that live or videobased contact with people with mental health problems were the most effective interventions in improving attitudes and reducing desire for social distance. Evidence from one

Table 1 Key ingredients of anti-stigma programmes for healthcare providers

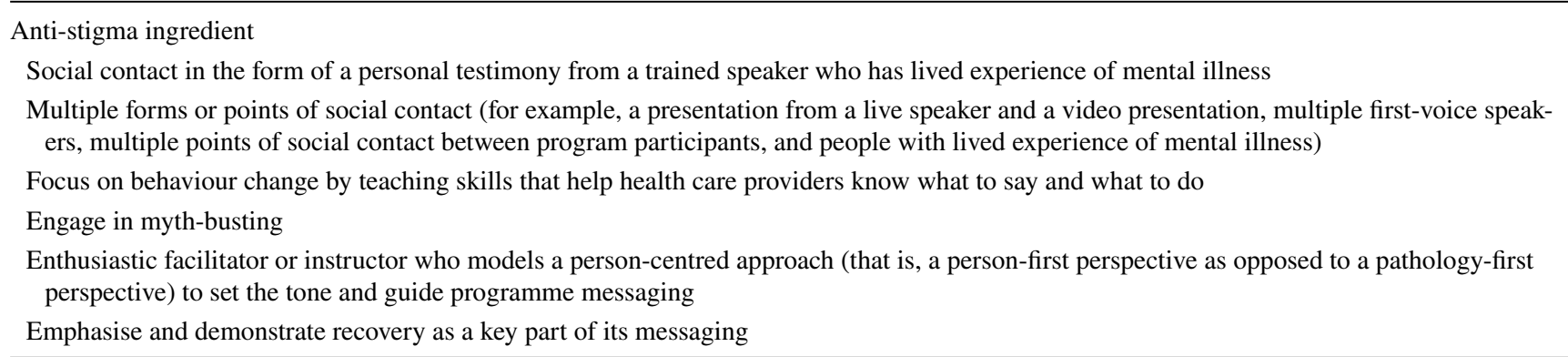

Based on findings reported on p. S21-22 in [42] 
study suggested that providing treatment information might enhance students' attitudes towards the use of services [52].

\section{Research on anti-stigma interventions: the state of the art}

Several reviews using systematic search strategies and either meta-analytic or narrative synthesis together provide a valuable summary of both the evidence for anti-stigma interventions and the state of the art in terms of evaluation methods. Reviewers have variously chosen to categorise interventions based on the anti-stigma strategy [24]; medium used [53]; type of stigma and mental disorder [54]; and length of follow-up, outcomes measured and setting [55]. While the scope of these reviews leads to extensive overlap in the papers included, this variety of categorisations makes their results difficult to compare. The various terms used for contact which is other than direct face to face contact obscures their broad similarity as forms of parasocial contact [56]. We therefore use this term in Table 2, which summarises the evidence from systematic reviews and, where not covered by systematic reviews, individual studies.

A narrative review [57], conducted at the same time as one of the aforementioned systematic reviews [55] but using a broader search strategy, summarised what is known about evaluation methods for anti-stigma interventions. It was noted that studies are heterogeneous and commonly have methodological limitations (e.g. weak study designs, small samples); Low and Middle Income Country data is notably missing; and long-term follow-up data and insights on how improvements can be sustained are needed, as are studies considering service-user perspectives and discrimination and behaviour change. Last, many national programmes target both the general public and specific target groups without control groups, making it difficult to disentangle the effects of samples in target groups who may receive both interventions.

Overall, anti-stigma interventions appear to result in small-to-moderate-sized effects (as assessed using Cohen's interpretation; [58]), and strategies based on direct or parasocial contact. At the population level, evidence points towards anti-stigma interventions resulting in improved attitudes, at least in the short term. There is also some evidence for improvements in knowledge. For anti-stigma efforts amongst specific target groups, interventions based on contact likewise seem to result in short-term benefits in terms of improved attitudes, but there is less evidence for achieving changes in knowledge.

\section{Directions for future interventions and research}

Intervening to reduce stigma and discrimination requires a long-term, sustained commitment [59]. However, the need to improve the evaluation methods and the interventions themselves is urgent.

While contact-based education has become the most popular method for work with target groups, the evidence for its long-term impact is limited [55] and there is evidence that education is relatively more effective for youth [24]. To try to increase the effectiveness of both direct and parasocial contact, closer attention could be paid to existing literature on intergroup contact when designing and evaluating such interventions. For example, Knaak and colleagues identified six ingredients for contact-based education with health professionals [42], without relating these to the ingredients previously identified by intergroup contact theory. In contrast, another study [60] examined changing negative attitudes amongst students towards a confederate classified as a 'former mental patient', with an approach explicitly informed by Allport's theory on intergroup attitudes and contact [61]. Allport's 'contact hypothesis' proposes that for contact between members of in- and
Table 2 Summary of evidence on interventions to reduce stigma

\begin{tabular}{lll}
\hline Type of intervention or nonexperimental exposure & Knowledge and attitudes & Behaviour \\
\hline Short term face to face contact & $+\mathrm{SR}$ & $-\mathrm{SR}$ \\
Short term parasocial contact & $+\mathrm{SR}$ & $-\mathrm{SR}$ \\
Long term face to face contact $^{\mathrm{a}}$ & $+\mathrm{IS}[37,38]$ & $-\mathrm{SR}$ \\
Long-term parasocial contact (with or without other & $+\mathrm{IS}($ see section on "Anti-stigma & + IS [39] \\
$\quad$ interventions) & interventions for the general public") & \\
Education & $+\mathrm{SR}$ & $-\mathrm{SR}$ \\
Protest & $-\mathrm{SR}$ & $-\mathrm{SR}$ \\
Structural approaches & $-\mathrm{SR}$ & $-\mathrm{SR}$ \\
\hline
\end{tabular}

Key: + positive evidence; - evidence lacking; SR evidence from one or more systematic reviews; IS evidence from one or more individual studies [study references in brackets]

${ }^{a}$ Long-term contact through knowing someone with a mental illness 
out-groups to lead to favourable outcomes for the outgroup member, the two groups need to be afforded equal status during the interaction, and the interaction needs to involve a mutual goal. The study followed these principles, and incorporated other conditions identified in existing literature as necessary for successful intergroup contact: the opportunity to get to know the out-group member during the interaction; interaction disconfirming negative stereotype; active co-operation; and interaction including a guiding structure. After co-operative contact activities, initially prejudiced students not only described the 'mental patient' confederate more positively, but these improvements also generalised beyond this specific individual to the out-group overall.

Intergroup contact researchers in the UK [62] have discussed the application of intergroup contact theory to mental health-related stigma. This work examined the influence of different types of imagined contact with people with schizophrenia, and concluded that imagined contact might in in this case increase intergroup anxiety (and thus desire for social distance) unless it was purposefully structured to reflect a positive imagined contact experience. When designing anti-stigma interventions, it is therefore important to consider what factors mediate the effectiveness of intergroup contact-based strategies. A meta-analysis of over 500 studies [63] confirmed that contact can diminish prejudice through resulting in reduced anxiety about contact, and increased empathy and perspective taking. A further key factor was enhanced knowledge regarding the outgroup, however, the mediational value of this influence was weaker than that of reduced anxiety and increased empathy. More recently, the importance of threats, both realistic and symbolic, perceived by one group about the other have been identified as important mediators [56]. Realistic threats include that of violence or loss of access to resources as a result of increased contact with another group; symbolic threats are those to the values and beliefs of a group.

These mediators should be considered when designing interventions for target groups. Anxiety and perceived realistic threat are likely to be high in groups with little prior contact or knowledge, such as the general population and in particular young people. These were found to be important mediators in a study of the relationship between contact and desired avoidance among students [64]. On the other hand, groups with frequent contact are unlikely to have high levels of anxiety. Studies of stigma among health professionals have been suggested to show that clinical contact may not reduce stigma, however the circumstances of the contact have rarely been examined in relationship to intergroup contact theory. Equal status is not typical in clinical encounters with health professionals but is important for contact to succeed [65]. Intergroup contact theory likewise highlights the importance of stereotype disconfirmation and acquaintanceship; aspects which may be harder to achieve when mental health professionals see only those most severely affected by mental illness and at the times when they are most ill, and over short periods of time. Loss of empathy, for example due to short term stress or longer term burnout [66], may be a relatively more important mediator in this and other groups with contact under circumstances which are not ideal, such as emergency services personnel. Further, the type of knowledge which is effective may vary depending on the target group. Biological knowledge has been suggested as potentially having a positive effect on doctors' attitudes [67], while a metaregression of public attitudes surveys suggested that agreement with biological causal explanations of mental illness among the general population may have a negative effect [68].

A warning note to programmes planning or delivering contact-based interventions regards a possible unintended consequence, namely lack of progress in addressing structural discrimination. Anti-stigma programmes may try to target structural level discrimination through inclusion of target groups such as employers or health professionals. However, governmental funders of anti-stigma programmes may prefer to pay for contact and educational interventions with the aim of reducing interpersonal stigma rather than face the possible financial implications of addressing structural discrimination; likewise, stakeholders such as employers may prefer to receive interpersonal stigma interventions. While providing contact-based education may be effective in improving the experience of people with mental health problems either as employees or service users, there is a danger that this results in reduced attention and effort in relation to structural change [56]. Measuring structural discrimination is complex but a number of approaches have been recently reviewed along with the evidence for its impact and the effects of addressing it [69].

The effectiveness of intergroup contact is exploited by anti-stigma programmes in several ways. For those with no familiarity, they provide parasocial contact. They may also enhance the effectiveness of pre-existing face to face contact through familiarity with a friend, relative or colleague; raising awareness or increasing mental health literacy may cause people to realise they know someone with a mental health problem, and the existence of such campaigns reflects institutional support for this contact, an important ingredient for successful contact [61]. Strategies such as Time to Change's 'Time to Talk Day' (http:// www.time-to-change.org.uk/timetotalkday) may encourage extended contact, that is, the effect of having a friend who knows someone with a mental illness. Extended contact has been shown to be associated with lower prejudice regarding other groups [56]. However, the influence of extended 
contact also has potentially negative consequences. Selective description of people with mental illnesses or of events involving them such as by health professionals or emergency services personnel may act to confirm stereotypes, for example anecdotes of violent incidents or severe disability. On the other hand, these professionals are also potential anti-stigma agents through extended contact should they give others a more balanced view of their work. To our knowledge, this potential has not so far been exploited by anti-stigma programmes.

We identify three further means to maximise the effectiveness of interventions for target groups. First, preparatory work can increase the understanding of the target group and the context of their contact with the stigmatised group [70], for example using qualitative interviews or ethnography to inform intervention design. This can inform, for example, the choice of contact type between face to face versus parasocial contact, which is more appropriate in settings in which disclosure poses risks for people with mental illness and/or their family members. These methods could also elucidate the influences of structural and organisational level discrimination on individual level interactions and the experience of people with mental health problems [32, 71], allowing the identification of structural level interventions. Second, it should be noted that in both England and Canada, there were gender-based differences in responses to the anti-stigma programmes, with men reporting less contact with people with a mental illness than women. As such contact is important for improved stigma reduction outcomes, future efforts might benefit from gender-based approaches [30]. Last, those with pedagogical expertise could be involved to ensure the use of evidencebased teaching and assessment methods when conducting skills training.

Regarding evaluation methods, our general design recommendations include: randomised designs for interventions tailored to specific groups; improved reporting of study procedures; validated and appropriate outcome measures which match the intervention content, including measures of behaviour and impact on people with mental health problems; better controlling for confounding factors and potential social desirability bias [72]; increased sample sizes; better sampling procedures to increase representativeness, and follow-up data collection beyond the immediate end of the intervention. Process evaluation to assess the context, implementation and mechanisms of action [73] of interventions would facilitate the delivery of more effective interventions in future. An example is the process model developed by Knaak and colleagues [74]. As it seems that short-term interventions often only have a short-term impact, the implication is that we need to study longer term interventions and to use the interim process and outcome data to improve the interventions along the way.
Evidence on the long-term impact of longer term interventions such as national anti-stigma programmes using mass media is hard to obtain; however, it is hard to show a causal association in these circumstances. While it is not usually possible to conduct randomised studies of population-based interventions, other quasi-experimental designs [75] should be considered to examine the extent to which change is attributable to the campaign rather than to secular changes. Otherwise, the use of repeated surveys can be used not just to assess changes in outcomes over time, but to examine whether the outcomes are associated with campaign awareness on the part of the target group [76, 77].

The many directions which could be taken by antistigma interventions and their evaluation make this an exciting and challenging field. For those working in this field, there is a balance to strike if we are to better identify effective and replicable interventions. On one hand, we must acknowledge that the goals of those who deliver programmes and those who evaluate them overlap only partially; while evaluators want to find positive results they must work independently so that their results are credible and informative. On the other, collaboration is essential if we are to realise the potential of developing and applying theory-based interventions and evaluation designs.

Acknowledgements PCG received funding support from the National Institute for Health Research (NIHR) Mental Health Biomedical Research Centre at South London and Maudsley NHS Foundation Trust and King's College London. GT is supported by the National Institute for Health Research (NIHR) Collaboration for Leadership in Applied Health Research and Care South London at King's College London Foundation Trust. The views expressed are those of the authors and not necessarily those of the NHS, the NIHR or the Department of Health. GT acknowledges financial support from the Department of Health via the National Institute for Health Research (NIHR) Biomedical Research Centre and Dementia Unit awarded to South London and Maudsley NHS Foundation Trust in partnership with King's College London and King's College Hospital NHS Foundation Trust. GT is supported by the European Union Seventh Framework Programme (FP7/2007-2013) Emerald project.

\section{Compliance with ethical standards}

Conflict of interest $\mathrm{CH}$ has received consulting fees from Lundbeck. GT has received grants for stigma-related research in the past five years from the National Institute for Health Research, and has acted as a consultant to the UK Office of the Chief Scientist. CH and GT have received grants for the evaluation of Time to Change, which is funded by the UK department of Health, Big Lottery Fund, and Comic Relief. TD has no conflicts to declare.

Open Access This article is distributed under the terms of the Creative Commons Attribution 4.0 International License (http:// creativecommons.org/licenses/by/4.0/), which permits unrestricted use, distribution, and reproduction in any medium, provided you give appropriate credit to the original author(s) and the source, provide a link to the Creative Commons license, and indicate if changes were made. 


\section{References}

1. Pescosolido BA, Martin JK (2015) The stigma complex. Annu Rev Sociol 41:87-116. doi:10.1146/ annurev-soc-071312-145702

2. Clement S, Schauman O, Graham T et al (2015) What is the impact of mental health-related stigma on help-seeking? A systematic review of quantitative and qualitative studies. Psychol Med 45:11-27. doi:10.1017/S0033291714000129

3. Corrigan PW, Druss BG, Perlick DA (2014) The impact of mental illness stigma on seeking and participating in mental health care. Psychol Sci Public Interest 15:37-70. doi:10.1177/1529100614531398

4. Mai Q, Holman CDJ, Sanfilippo FM et al (2011) Mental illness related disparities in diabetes prevalence, quality of care and outcomes: a population-based longitudinal study. BMC Med. doi:10.1186/1741-7015-9-118

5. Laursen TM, Munk-Olsen T, Nordentoft M, Mortensen PB (2007) Increased mortality among patients admitted with major psychiatric disorders: a register-based study comparing mortality in unipolar depressive disorder, bipolar affective disorder, schizoaffective disorder, and schizophrenia. J Clin Psychiatry 68:899-907

6. Gissler M, Laursen TM, Oesby U et al (2013) Patterns in mortality among people with severe mental disorders across birth cohorts: a register-based study of Denmark and Finland in 19822006. BMC Public Health. doi:10.1186/1471-2458-13-834

7. Suhrcke M, de Paz Nieves C (2011) The impact of health and health behaviors on educational outcomes in high-income countries: a review of the evidence. WHO Regional Office for Europe, Copenhagen

8. Lee S, Tsang A, Breslau J et al (2009) Mental disorders and termination of education in high-income and low and middleincome countries: Epidemiological study. $\mathrm{Br} \mathrm{J}$ Psychiatry 194:411-417. doi:10.1192/bjp.bp.108.054841

9. Social Exclusion Unit (2004) Mental health and social exclusion. Office of the Deputy Prime Minister, London

10. Clement S, Brohan E, Sayce L et al (2011) Disability hate crime and targeted violence and hostility: a mental health and discrimination perspective. J Ment Heal 20:219-225. doi:10.3 109/09638237.2011.579645

11. Thornicroft G (2006) Shunned: discrimination against people with mental illness. Oxford University Press, Oxford

12. Link BG, Phelan JC (2006) Stigma and its public health implications. Lancet 367:528-529. doi:10.1016/ S0140-6736(06)68184-1

13. Thornicroft G, Evans-Lacko S, Henderson C (2014) Stigma and discrimination. In: Davies SC (ed) Annual Report of the Chief Medical Officer 2013, Public Mental Health Priorities: Investing in the Evidence. Department of Health, London

14. Department of Health (2011) No health without mental health. HM Government, London

15. World Health Organisation (2013) Mental health action plan 2013-2020. doi:10.1017/CBO9781107415324.004

16. Schulze B (2007) Stigma and mental health professionals: a review of the evidence on an intricate relationship. Int Rev Psychiatry 19:137-155. doi:10.1080/09540260701278929

17. Corrigan PW, River LP, Lundin RK et al (2001) Three strategies for changing attributions about severe mental illness. Schizophr Bull 27:187-195. doi:10.1093/oxfordjournals.schbul.a006865

18. Jorm AF (2012) Mental health literacy: Empowering the community to take action for better mental health. Am Psychol 67:231-243. doi:10.1037/a0025957

19. Kitchener BA, Jorm AF (2004) Mental health first aid training in a workplace setting: A randomized controlled trial [ISRCTN13249129]. BMC Psychiatry 4:23. doi:10.1186/1471-244X-4-23

20. Jorm AF, Kitchener BA, Fischer J-A, Cvetkovski S (2010) Mental health first aid training by e-learning: a randomized controlled trial. Aust N Z J Psychiatry 44:1072-1081. doi:10.3 109/00048674.2010.516426

21. Cumming E, Cumming J (1957) Closed ranks: an experiment in mental health education. Harvard University Press, Cambridge

22. Priest RG (1991) A new initiative on depression. Br J Gen Pract 41:487

23. Henderson C, Noblett J, Parke H et al (2014) Mental healthrelated stigma in health care and mental health-care settings. Lancet 1:467-482. doi:10.1016/S2215-0366(14)00023-6

24. Corrigan PW, Morris S, Michaels P et al (2012) Challenging the public stigma of mental illness: a meta-analysis of outcome studies. Psychiatr Serv 63:963-973. doi:10.1002/9780470977507. ch3

25. Morgan A, Jorm A (2007) Awareness of beyondblue: the national depression initiative in Australian young people. Australas Psychiatry 15:329-333. doi:10.1080/10398560701323976

26. Jorm AF, Christensen H, Griffiths KM (2005) The impact of beyondblue: the national depression initiative on the Australian public's recognition of depression and beliefs about treatments. Aust N Z J Psychiatry 39:248-254. doi:10.1111/j.1440-1614.2005.01561.x

27. Thornicroft C, Wyllie A, Thornicroft G, Mehta N (2014) Impact of the "Like Minds, Like Mine" anti-stigma and discrimination campaign in New Zealand on anticipated and experienced discrimination. Aust N Z J Psychiatry 48:360-370. doi: $10.1177 / 0004867413512687$

28. Mehta N, Kassam A, Leese M et al (2009) Public attitudes towards people with mental illness in England and Scotland, 1994-2003. Br J Psychiatry 194:278-284. doi:10.1192/bjp. bp. 108.052654

29. Hansson L, Stjernswärd S, Svensson B (2016) Changes in attitudes, intended behaviour, and mental health literacy in the Swedish population 2009-2014: an evaluation of a national antistigma programme. Acta Psychiatr Scand 134:S71-S79. doi:10.1111/acps.12609

30. Henderson C, Stuart H, Hansson L (2016) Lessons from the results of three national antistigma programmes. Acta Psychiatr Scand 134:S3-S5. doi:10.1111/acps.12605

31. Thornicroft G, Rose D, Kassam A, Sartorius N (2007) Stigma: ignorance, prejudice or discrimination? Br J Psychiatry 190:192193. doi:10.1192/bjp.bp.106.025791

32. Link BG, Phelan JC (2001) Conceptualizing stigma. Annu Rev Sociol 27:363-385. doi:10.1146/annurev.soc.27.1.363

33. Link BG, Yang LH, Phelan JC, Collins PY (2004) Measuring mental illness stigma. Schizophr Bull 30:511-541

34. Friedrich B, Evans-Lacko S, London J et al (2013) Anti-stigma training for medical students: the education not discrimination project. Br J Psychiatry 202:s89-s95. doi:10.1192/bjp. bp.112.114017

35. Henderson C, Williams P, Little K, Thornicroft G (2013) Mental health problems in the workplace: changes in employers' knowledge, attitudes and practices in England 2006-2010. Br J Psychiatry 202:s70-s77. doi:10.1192/bjp.bp.112.112938

36. Stuart H, Chen S-P, Christie R et al (2014) Opening minds in Canada: background and rationale. Can J Psychiatry 59:S8-S12

37. Evans-Lacko S, Malcolm E, West K et al (2013) Influence of Time to Change's social marketing interventions on stigma in England 2009-2011. Br J Psychiatry Suppl 202:s77-s88. doi:10.1192/bjp.bp.113.126672

38. Henderson C, Robinson E, Evans-Lacko S et al (2016) Public knowledge, attitudes, social distance and reported contact 
regarding people with mental illness 2009-2015. Acta Psychiatr Scand 134:S23-S33. doi:10.1111/acps.12607

39. Corker E, Hamilton S, Robinson E et al (2016) Viewpoint survey of mental health service users' experiences of discrimination in England 2008-2014. Acta Psychiatr Scand 134:S6-S13. doi:10.1007/s00127-014-0875-3

40. Koller M, Stuart H (2016) Reducing stigma in high school youth. Acta Psychiatr Scand 134:S63-S70. doi:10.1111/acps.12613

41. Knaak S, Patten S (2016) A grounded theory model for reducing stigma in health professionals in Canada. Acta Psychiatr Scand 134:S53-S62. doi:10.1111/acps.12612

42. Knaak S, Modgill G, Patten SB (2014) Key ingredients of anti-stigma programs for health care providers: a data synthesis of evaluative studies. Can J Psychiatry Rev Can Psychiatr 59:S19-S26

43. Corrigan PW (2004) Target-specific stigma change: a strategy for impacting mental illness stigma. Psychiatr Rehabil J 28:113121. doi:10.2975/28.2004.113.121

44. Patterson P, Whittington R, Bogg J (2007) Measuring nurse attitudes towards deliberate self-harm: the self-harm antipathy scale (SHAS). J Psychiatr Ment Health Nurs 14:438-445. doi:10.1111/j.1365-2850.2007.01102.x

45. Graham AL, Julian J, Meadows G (2010) Improving responses to depression and related disorders: evaluation of a innovative, general, mental health care workers training program. Int J Ment Health Syst. doi:10.1186/1752-4458-4-25

46. Bayar MR, Poyraz BC, Aksoy-Poyraz C, Arikan MK (2009) Reducing mental illness stigma in mental health professionals using a web-based approach. Isr J Psychiatry Relat Sci 46:226-230

47. Irvine BA, Billow MB, Bourgeois M, Seeley JR (2012) Mental illness training for long term care staff. J Post-Acute Long-Term Care Med 13(81):e7-81.e13. doi:10.1016/j.jamda.2011.01.015

48. Modgill G, Patten SB, Knaak S et al (2014) Opening minds stigma scale for health care providers (OMS-HC): examination of psychometric properties and responsiveness. BMC Psychiatry 14:120. doi:10.1186/1471-244X-14-120

49. Pinfold V, Huxley P, Thornicroft G et al (2003) Reducing psychiatric stigma and discrimination - evaluating an educational intervention with the police force in England. Soc Psychiatry Psychiatr Epidemiol 38:337-344. doi:10.1007/s00127-003-0641-4

50. Hansson L, Markström U (2014) The effectiveness of an anti-stigma intervention in a basic police officer training programme: a controlled study. BMC Psychiatry 14:55. doi:10.1186/1471-244X-14-55

51. Yamaguchi S, Wu S-I, Biswas M et al (2013) Effects of shortterm interventions to reduce mental health-related stigma in university or college students: a systematic review. J Nerv Ment Dis 201:490-503. doi:10.1097/NMD.0b013e31829480df

52. Sharp W, Hargrove DS, Johnson L, Deal WP (2006) Mental health education: an evaluation of a classroom based strategy to modify help seeking for mental health problems. J Coll Stud Dev 47:419-438

53. Clement S, Lassman F, Barley E et al (2013) Mass media interventions for reducing mental health-related stigma. Cochrane Database Syst Rev 7:CD009453

54. Griffiths KM, Carron-Arthur B, Parsons A, Reid R (2014) Effectiveness of programs for reducing the stigma associated with mental disorders. A meta-analysis of randomized controlled trials. World. Psychiatry 13:161-175. doi:10.1002/wps.20129

55. Mehta N, Clement S, Marcus E et al (2015) Evidence for effective interventions to reduce mental health-related stigma and discrimination in the medium and long term: systematic review. $\mathrm{Br}$ J Psychiatry 207:377-384. doi:10.1192/bjp.bp.114.151944

56. Al Ramiah A, Hewstone M (2013) Intergroup contact as a tool for reducing, resolving, and preventing intergroup conflict: evidence, limitations, and potential. Am Psychol 68:527-542. doi:10.1037/a0032603

57. Thornicroft G, Mehta N, Clement S et al (2016) Evidence for effective interventions to reduce mental-health-related stigma and discrimination. The Lancet 387:1123-1132. doi:10.1016/ S0140-6736(15)00298-6

58. Cohen J (1988) Statistical power analysis for the behavioral sciences. Erlbaum, Hillsdale, NJ

59. Sartorius N (2010) Short-lived campaigns are not enough. Nature 468:163-165. doi:10.1038/468163a

60. Desforges DM, Lord CG, Ramsey SL et al (1991) Effects of structured cooperative contact on changing negative attitudes toward stigmatized social groups. J Pers Soc Psychol 60:531544. doi:10.1037/0022-3514.60.4.531

61. Allport GW (1954) The nature of prejudice. Addison-Wesley, Reading

62. West K, Holmes E, Hewstone M (2011) Enhancing imagined contact to reduce prejudice against people with schizophrenia. Gr Process Intergr Relat 14:407-428. doi:10.1177/1368430210387805

63. Pettigrew TF, Tropp LR (2008) How does intergroup contact reduce prejudice? Meta-analytic tests of three mediators. Eur J Soc Psychol 38:922-934. doi:10.1002/ejsp

64. West K, Hewstone M, Lolliot S (2014) Intergroup contact and prejudice against people with schizophrenia. J Soc Psychol 154:217-232. doi:10.1080/00224545.2014.888327

65. Pettigrew TF, Tropp LR (2000) Does intergroup contact reduce prejudice: recent meta-analytic findings. In: Oskamp $S$ (ed) Reducing Prejud. Discrim. Erlbaum, Kahwah, pp 93-114

66. Hayes SC, Bissett R, Roget $N$ et al (2004) The impact of acceptance and commitment training and multicultural training on the stigmatizing attitudes and professional burnout of substance abuse counselors. Behav Ther 35:821-835

67. Knaak S, Ungar T, Patten S (2015) Seeing is believing: Biological information may reduce mental health stigma amongst physicians. Aust N Z J Psychiatry 49:751-752. doi:10.1177/0004867415584643

68. Schomerus G, Schwahn C, Holzinger A et al (2012) Evolution of public attitudes about mental illness: a systematic review and meta-analysis. Acta Psychiatr Scand 125:440-452. doi:10.1111/j.1600-0447.2012.01826.x

69. Hatzenbuehler ML (2016) Structural stigma: Research evidence and implications for psychological science. Am Psychol 71:742-751. doi:10.1037/amp0000068

70. Ungar T, Knaak S, Szeto AC (2016) Theoretical and practical considerations for combating mental illness stigma in health care. Commun Ment Health J 52:262-271. doi:10.1007/ s10597-015-9910-4

71. Schulze B, Angermeyer MC (2003) Subjective experiences of stigma. A focus group study of schizophrenic patients, their relatives and mental health professionals. Soc Sci Med 56:299-312. doi:10.1016/S0277-9536(02)00028-X

72. Henderson C, Evans-Lacko S, Flach C, Thornicroft G (2012) Responses to mental health stigma questions: the importance of social desirability and data collection method. Can J Psychiatry $57: 152-160$

73. Moore G, Audrey S, Barker M, et al (2014) Process evaluation of complex interventions. UK Medical Research Council (MRC) guidance. https://www.mrc.ac.uk/documents/pdf/mrcphsrn-process-evaluation-guidance-final/. Accessed $20 \mathrm{Sept}$ 2016

74. Knaak S, Patten SB (2014) Building and delivering successful anti-stigma programs for healthcare workers. Results of a qualitative study. Mental Health Commission of Canada, Calgary

75. Gilbody S, Whitty P (2002) Improving the delivery and organisation of mental health services: beyond the conventional 
randomised controlled trial. $\mathrm{Br} \mathrm{J}$ Psychiatry 180:13-18. doi:10.1192/bjp.180.1.13

76. Sampogna G, Bakolis I, Robinson E, et al Experience of the Time to Change programme in England as predictor of mental health service users' stigma coping strategies. Epidemiol Psychiatr Sci. doi:10.1017/S204579601600041X
77. Sampogna G, Bakolis I, Evans-Lacko S et al (2016) The impact of social marketing campaigns on reducing mental health stigma: results from the 2009-2014 Time to Change programme. Eur Psychiatry 40:116-122. doi:10.1016/j.eurpsy.2016.08.008 